\section{Carcinoma of the Prostate}

Q. - A man of 61 had a small hard carcinoma of the prostate with a serum acid phosphatase of 38.5 units. On stilboestrol and iron his symptoms have disappeared. The prostate now feels normal, small and soft, and the serum acid phosphatase reading is 0.9 Gutman units. What is the prognosis in this case? Is it possible to say what is the expectation of life, and is it possible to give any idea of how such a case would end?

A. - The immediate response of this patient with carcinoma of the prostate to stilboestrol therapy is satisfactory, and the improvement is confirmed by the fall in the serum acid phosphatase reading. It is difficult to state an expectation of life, but patients live for several years, and the writer knows of one patient who with this treatment is alive eight years after the diagnosis was made. As to possible termination of the disease, severe deterioration from widespread skeletal metastases might occur, or complications affecting the urinary tract, including renal failure.

\section{Effort Syndrome and Thyroid Extract}

0.-A patient suffering from severe loss of weight and effort syndrome following influenza and several apical abscesses, which were treated, has been given thyroid tablets, $\frac{1}{2}$ gr. (32 $\mathrm{mg}$.) daily, as a general tonic. Is this sound?

A.- Thyroid seems to be entirely contraindicated in the circumstances mentioned: it is not a tonic; it increases weight loss ; and it might tend to exacerbate the symptoms of effort syndrome, which are often very similar to those of hyperthyroidism. In such a small dose as $\frac{1}{2}$ gr. daily, however, it would probably do little harm and would hardly have a significant effect upon the heart.

\section{Hepatic Tenderness following Amoebiasis}

Q. - What is the significance of a residual hepatic tenderness following a typical history of amoebic dysentery and hepatitis, treated fully with sulphaguanidine and penicillin; emetine; chiniofon and colonic lavage; and diodoquin? After treatment all examinations, including sigmoidoscopy, proved negative, except for hepatic tenderness, which has not decreased during the last two months. Are agglutination tests now used as criteria of cure in a case such as this?

A.- The presence of hepatic tenderness in a patient who at some time before has had amoebic dysentery is insufficient in itself to prove that the tenderness is in fact due to amoebiasis. From the data supplied in this particular case it is not possible to say what is the significance of the tenderness. Complement fixation tests have been used by some workers for the diagnosis of amoebiasis, but the results appear so inconsistent that the test should be regarded as experimental, and in the opinion of many it is of litthe practical value.

\section{Footprints for Identification}

Q.-Can you describe the best method of identifying infants? Is the taking of footprints adequate in this respect?

A.-Properly recorded footprints would undoubtedly be adequate for the solution of the practical problems of identification which occasionally arise in hospitals, nursing-homes, etc. From time to time a complete system of registration for the entire population has been advocated, including digital, palmar, and plantar prints, but the authorities have never considered that the circumstances warranted the introduction of such a system or that public opinion would be in favour of it.

\section{"Phenadoxone"}

Q.-In prescribing the synthetic analgesic "phenadoxone" is there any danger of addiction? Is this a suitable drug to administer for migraine or for repeated headaches. where an organic basis has been excluded and where tab. codeine co. has proved ineffective?

A.-Phenadoxone, which now comes under the provisions of the Dangerous Drugs Act, is definitely a drug of addiction, though not to the same extent as morphine, and to a much less extent than diamorphine (heroin). In consequence it is not a very suitable drug for repeated use in the treatment of a recurrent headache or for cases of migraine, for which ergotamine tartrate is a more specific and effective preparation.

\section{Drugs for Raising Blood Pressure}

Q.-Is there any drug which will consistently raise the blood pressure and keep it raised, and, if so, would this prevent vasovagal attacks?

A.- There is no drug which consistently raises the blood pressure and keeps it raised. Sublingual nor-adrenaline, however, is a useful quickly acting pressor agent which may be used to ward off impending vaso-vagal attacks.

\section{NOTES AND COMMENTS}

Prescription of P.A.S.-Messrs Ward, Blenkinsop, and Co. write: P.A.S. (para-aminosalicylic acid) is being increasingly prescribed by doctors for the treatment of pulmonary tuberculosis, but there appears to be some confusion whether para-aminosalicylic acid should be dispensed or its equivalent amount in the form of sodium para-aminosalicylate dihydrate. One hundred grammes of sodium para-aminosalicylate dihydrate, usually referred to as sodium P.A.S., is equivalent to $72.5 \mathrm{~g}$. of para-aminosalicylic acid, the accepted abbreviation for which is P.A.S. This compound is in most cases administered orally in the form of flavoured aqueous solutions, and the acid, being relatively insoluble, is not suitable for this purpose. On the other hand, sodium P.A.S. dissolves readily in water and aqueous solutions can easily be prepared.

It would therefore be helpful to pharmacists if this compound was prescribed in doses of the sodium salt-i.e., sodium P.A.S.-and not as P.A.S. unless the acid itself is specifically required. Furthermore, on storage aqueous solutions of sodium PAS darken in colour due to oxidation, and to a lesser degree decarboxylation may take place with the liberation of meta-aminophenol, resulting in a rise in $p \mathrm{H}$. Although the loss in potency of these solutions is not serious when stored for up to three months in well-filled, tightly closed containers in a cool place, it would be advisable for prescriptions to bear an indication that not more than one week's supply of solution should be prepared at a time. Alternatively, sodium P.A.S may be prescribed in packets containing individual doses. The patient then dissolves in water the contents of a packet at prescribed intervals and drinks the freshly prepared solution.

Gowers's Syndrome.-Dr. K. M. HAY (Birmingham) writes: I was interested in the remarks on Gowers's syndrome in "Any Questions ?" (May 13, p. 1156). I admit to being ignorant of the original description of the syndrome, and I have missed the recent references to it in the Journal. However, I have recently come across several patients subject to attacks of weakness, with facial pallor, cold perspiration, and usually headaches in addition. Glucose aborts the attacks, which may recur if not followed up within an hour or so by other food to maintain the blood sugar. We caught one boy of 11 years in an attack with a blood sugar of $57 \mathrm{mg}$. per $100 \mathrm{ml}$., and he recovered quickly with glucose. Some days later we attempted to induce a hypoglycaemia by exercising him on an empty stomach, and followed this up with a glucose tolerance test. All readings were well within the bounds of normality. We have collected some data on a number of these cases, but not enough to do more than offer this idea as a suggestion. There is reason to believe that these hypoglycaemic symptoms can occur in those so predisposed in conditions of chronic fatigue. It is probable that mild symptoms of hypoglycaemia are commoner than is realized. In spite of canteens and numerous tea interludes quite a few people can be found who do strenuous work for up to six hours or more without taking any food Needless to say the syndrome is rare in those offices where tea intervals are frequent. Such a theory would not explain the case mentioned in the question. Would it be possible that for some reason or other something akin to the dumping syndrome is responsible for the symptoms described in this patient ?

Correction.-In the article entitled "A Newly Discovered Portrait of William Harvey" (May 27, p. 1259) we omitted to give the price of The Portraiture of William Harvey. It is $25 \mathrm{~s}$.

All communications with regard to editorial business should be addressed to $T_{H}$ EDITOR, BRITISH MEDICAL JOURNAL, B.M.A. HOUSE, TAVISTOCK SQUARE, LONDON, W.C.1. TELEPHONE: EUSTON 2111. TELEGRAMS: Aitiology, publicent, London. ORIGINAL ARTICLES AND LETTERS forwarded for publication are understood to be offered to the British Medical Journa! alone. Authors desiring REPRINTS should communicate with the Publish B.M.A. House, Tavistock Square, W.C.1, on receipt of proofs.
ADVERTISEMENTS should be addressed to the Advertisement Manager. B.M.A. House Tavistock Square, addessed to the Advertisement Manager. TELEPHONE : EUSTON 2111. TELEGRAMS : Britmedads. Westcent, London. MEMBERS' SUBSCRIPTIONS should be sent to the SECRETARY of the Association. TelePHONE: EUSTON 2111. TElegrams: Medisecra, Westcent, London.

B.M.A. Scottish OFfice: 7, Drumsheugh Gardens, Edinburgh. 